\title{
Green Economy: Researching Working from Home in Building Sector
}

\author{
Nurul Adilah Saludin ${ }^{1}$, Noorliza Karia ${ }^{2}$ and Hasnanywati Hassan ${ }^{1}$ \\ ${ }^{1}$ School of Housing, Building and Planning, Universiti Sains Malaysia, Penang, Malaysia \\ ${ }^{2}$ School of Management, Universiti Sains Malaysia, Penang, Malaysia
}

Correspondence should be addressed to: Nurul Adilah Saludin; adyla88@gmail.com

Received 9 January 2013; Accepted 12 June 2013; Published 28 November 2013

Academic Editor: Sabitha Marican

Copyright (C) 2013 Nurul Adilah Saludin, Noorliza Karia and Hasnanywati Hassan. Distributed under Creative Commons CC-BY 3.0

\begin{abstract}
The rapid growth of telework or working from home (WFH) is inspired by the growth in knowledge-based economy, rapid technology progress, virtual operations and digital workforce. The original push on teleworking as a tool for cutting traffic congestion and improving air quality did not lead to large-scale adoption of teleworking in Malaysia. Indeed the research of WFH in Malaysia is scarce and its implementation among the organizations almost unavailable even though the nation is moving towards promoting green economy. However, with the sustainability and green concerns, teleworking can be considered a part of firm's strategic and innovative to enhance competitive advantage which may lead to economic and environmental improvement. Thus the emerging trend for sustainable growth (e.g. quality education, modern workforce, green innovation, knowledge and digital society) has inspired this research to seek the benefits of working from home (WFH), factors that trigger WFH and basic requirements for WFH to be initiated have been unearthed by many researchers and implemented by many developed countries in the world. This paper explores the literature on WFH in some of the developed countries and the topic of WFH in Malaysian scenario is discussed by proposing a framework for future research to be carried out by Malaysian organizations.
\end{abstract}

Keywords: Working from home, teleworking, green economy, sustainable development.

\section{Introduction}

Teleworking is the significant element of a modern economy, facilitating the organization of work by using information and communication technologies that enable employees and managers to access their labor activities from remote locations such as home-based teleworking, mobile teleworking or teleworking center. Teleworking emphasize more on environment that allows employees to work from home which drive solutions for reducing commuting, balance work and family, increasing productivity and protect ecosystem (Asaari and Karia, 2001). The nature of our ecosystem implies that when we offer services to people with the intention to make profit or not, we are complied to protect our planet. The world's climate is crucial and the awareness on the importance of environmental performance (e.g., reduce $\mathrm{CO}_{2}$ emission and waste) has brought teleworking become more 
significant since 1970s (Perez et al., 2004). Such responsibility theory on people, profit and planet (3P) justifies the increasing number to over 20 million workers in the U.S. engaged in teleworking (Golden, 2006). Furthermore literature acknowledges that all across industry affect significantly the environment by increasing $\mathrm{CO}_{2}$ emissions from transport vehicles and vessels which generate global warming. Therefore teleworking should be a prominent principle for every firm in Malaysia as it provides the solution for both the economic and environmental improvement. The facts are that not many firms in Malaysia are engaged in teleworking and the number of existence teleworkers is unknown, although teleworking has asserted to reduce $\mathrm{CO}_{2}$ and save energy.

Most researchers claimed that with teleworking, the employees can definitely achieve a balance between work and personal life commitments. The individual, organization and societal benefits are known to be obtained if teleworking is implemented. Economic and environmental improvements are perceived to be the known improvements in the way of life for many teleworking stakeholders. Organizational implications, global workforce implications and the scarcity of scholarly publications make this research topic one that warrants our further investigation. Information technology, financing, service, technology and advertising are some of the industries that adopt teleworking for their employees as carried out by many researchers. Financial industry is often in the forefront when it comes to the introduction of new work practices such as teleworking. The construction industry research of teleworking however has never been carried out when the subject is discussed in the parameter. Thus WFH in building sector is essential to accelerate national economy and promote sustainable development.

Working from home (WFH) is a common work style for most developed countries. Most developed countries have carried out the concept in their working life since in the $70 \mathrm{~s}$. What is more, WFH is known to serve better work-life style and can give many advantages to the company and employee such as realestate cost savings, productivity increase, less absenteeism, labour relations flexibility, better customer service, flexibility, and cost savings in commuting. Other than that, the main reasons attributed to the potential growth of telecommuting in many developed countries include flexibility, reduced office overheads, energy consumption, increase in worker's productivity, improved recruitment opportunities particularly for female employees, reduction in travel fatigue, travel time, travel cost, parking fees, savings on petrol, promotion of opportunities for dual income household, effective management of child care arrangements, increased family contact, ability to care for family illnesses, creation of employment opportunities in rural areas, positive environmental impacts by reduction in petrol consumption, pollution, traffic congestion and accident rates, flexible work arrangement for working mothers and job opportunities for disabled. Despite the positive WFH impact, Malaysia still has limited in-depth study on WFH (Perez et al., 2004; Hamsa et al., 1997; Asaari and Karia, 2001). Thus it is significant for this study to identify WFH implementation and further provide suggestion for Malaysian organizations to opt for WFH concept which has been discussed implicitly.

\section{Overview of WFH Development}

During 1950s, the literature on technological change led to the idea that telecommunications, combined with computing technology, could enable work to be relocated away from the traditional office (Baruch, 2000). The idea of WFH concept has been triggered by Jack Nilles in 1973 and 1979 due to the first international oil crisis that eventually give rise to concerns over petrol consumption, long work commutes, and traffic congestion in major metropolitan areas (Perez et al, 2004). Since then, according to Collins (2005), WFH began to be recognized widely throughout UK and Baruch (2000), said that WFH was 
expected to be the 'next workplace revolution' in the 1980s.

\section{Definition of $\mathrm{WFH}$}

Working from home is defined by working day spent in the home environment (Sayers et al., 2005). According to Hassan and Nuruddin. (2011), there are also various terms which are similar to Working from Home which is 'Teleworking', Telecommuting', 'Homeworking', and 'Working at Home'. Working from Home (WFH) will be used throughout this paper as a term to refer to the above definitions.

\section{WFH in Other Countries}

Nearly 7.6 million employees are now working from home in United States which constitutes approximately $4.8 \%$ of the total US work force. The industries which had taken a big stride in WFH include banking, insurance, financial services and legal industry. In United Kingdom, there are about 1.27 million telecommuters representing about $4.6 \%$ of the UK workforce. Rank Xerox and F International are the two major organizations that are practicing the concept of WFH in UK. Meanwhile, in Japan WFH is not really a preferable option because of the high cost of home residences in urban areas around cities like Tokyo. It is mostly because of the condition of the house which are small and it is really difficult to do the work at home. Therefore, the Japanese have experimented much more with Satellite offices as opposed to home working (Hamsa et al., 1997).

\section{Current Scenario of WFH in Malaysia}

Even though the teleworking has been promoted in Malayisa since 1990 (Hoon et al., 1999), still there is little acknowledgment for WFH implementation (Asaari and Karia, 2001) and it still remains unpopular in Malaysia even though there are many benefits that can be obtain from it (Ndubisi and Kahraman, 2005). The mobile workforce is relatively a new concept for the Malaysian workers (Hamsa et al., 1997). Apparently, there is a few multinational companies in the nation that have been adopting teleworking concept for their employees such as Amway International, IBM, American Insurance of Associates (AIA), Grand soft link computers, Motorola and Texas Instrument. However, teleworking concept has not been practices either part time or full time in the formal business organization in Malaysia. Formal business for the professionals such as in the construction industry has yet to apply the working from home concept. Therefore this paper explores the suitability and whether the concept is applicable to the industry. Proponents say telework makes the work force more efficient, cut costs and even helps protect the environment (CNN, 1996). Many companies are developing telework programs as a way to draw new employees. With today's tight labor market, companies that offer flexibility may have an edge over those who require all work to be done on site (Meyers, 1998). With the advancement of communications and information technology, the ability to log on the company's network with ease from any location as well as the availability of devices like notebook computers, smart mobile phones and hand held devices has given rise to a trend of mobile computing and teleworking (Anonymous, 1999).

There is evidence suggesting that WFH or telecommuting has been acknowledged by Malaysian companies and workers (Asaari and Karia, 2001; Karia and Assari, 2003; Karia and Asaari, 2006). The initial study suggests some variables for adopting WFH concept includes (1) savings and environment; (2) decision making and productivity; (3) job flexibility and satisfaction; (4) working condition and (5) family and personal matter (Assari and Karia, 2001). The findings show the reasons for WFH adoption however to implement such concept involve number of factors e.g. government supports, infrastructure and facilities, low-cost communication to be made available to everyone, low-cost computer power that allows electronic intelligence to be placed at home and electronic communication services which permit personal communication as opposed to broadcast communications. 
Furthermore the study conducted by Karia and Asaari (2003) on Malaysian public and private organizations identify the five determinants for telework such as (1) staff related concern on personal and family, (2) work-related, (3) staff's attitude, (4) work procedure and process; and (5) quality and delivery of work. The results imply that Malaysian managers are looking forward with the implementation of telecommuting concept in their organizations. They argued that top management supports are essential for the WFH adoption and implementation since it might enhance the performance of organization, employee, economic and environment in the long term. Another study on married women workers from Malaysian service industry points out that the work location transfer, working outstation and work satisfaction as the main motivators for them to adopt the teleworking concept (Karia and Asaari, 2006).

In Malaysia, new housing areas are relocated further away from the city centre, as the cities has become increasingly congested, and the employment centre concentrate or develop in the suburbia or fringe. The mean commuting distance increases in either case resulting in longer journeys to work, associated with stress, longer travel time, higher transportation cost, increased energy consumption, environmental concern, reduction in available workforce especially among pregnant women, nursing mothers and single parents who cannot afford long trips to work, marginalization of the handicapped from the workforce, pressure on available roads demanding huge investment on road infrastructures (Ndubisi and Kahraman, 2005). Thus WFH is an enabler for such problems encounter. Furthermore, the advancement and penetration of information technology, concentration of economic activities, travel congestion, environmental degradation, potential and limitation of women workforce, heavy investments in transportation infrastructure and long distance commuting are the key drivers towards WFH (Hamsa et al. (1997). Therefore, applying the concept WFH in the practice would be the best solutions to these problems. In order to WFH, the basic requirements perceived a person is able to WFH are discussed subsequently.

\section{Basic Requirements for WFH}

This research argues that teleworking is regarded as innovation that organization assimilates or uses which benefits and aims to increase operations competency and economic and environmental improvement as well. Innovation scholars regard innovation as an idea, practice or object that is perceived as new by individual or unit of adoption (Rogers, 1983) and other scholar regard innovation as initial use or intensive change and continue use or routinization of innovation (Damanpour, 1991; Tyre and Orlikawski, 1993). In this sense IT can play a role in building such a knowledge society for sustainability. Hence teleworking should be considered as a smart growth for firms to redesign or reposition their management and organizational structure. Given such critical arguments, research on the role of IT application in telework is still limited (Shin et al., 2000), hence it is significant to identify the suitable technology needed to support WFH.

To enable the concept of WFH being implemented, there are some basic requirements should be provided in advance such as computer, internet access, computer with fax capability, fax machine, telephone/handphone, pager (Asaari and Karia, 2001). Kurland and Bailey (1999) indicated that a person can be said to be a telecommuter if her telecommunications link to the office is as simple as a telephone, however telecommuters often use other communication media such as electronic mail, personal computer links to office servers and fax machine.

Other than that, Ndubisi and Kahraman (2005) also indicate that teleworking is information and communication technology aided work arrangement concerned with the use of personal computers, dedicated word processors or terminals, telephone, fax, email, modem, etc. But who are the one to prepare the equipment is rather subjective. Ahmadi et 
al. (2000) indicate that many companies require their telecommuters to provide their own equipment which often includes a PC with modem, phone and phone line as well as a fax machine. For example, Hewlett-Packard's telecommuters must purchase their own computer programs (Warner, 1997). But there are also other companies that are more supportive and provide these necessities at no charge.

\section{Factors towards WFH in Malaysia}

Most of the top management in a company would have a high concern towards the discipline of the employee regarding works, concentration on works, improvement on productivity, concern on quality of work delivered, and face-to-face contact (Karia and Assari, 2006). These factors are probably the reason why most companies in Malaysia still hesitating to adopt the concept of working from home in their company.

Asaari and Karia (2001) suggest factors that contribute to the acceptance of the working from home concept such as savings and the environment, decision making and productivity, job flexibility and satisfaction, working conditions, family and personal matters and it was found that, job flexibility and satisfaction; family and personal matters are the factors which have an impact on the telecommuting concept on an individual. The employees' perception on telecommuting concept conducted by Asaari and Karia (2001) confirm that factors related to job flexibility and satisfaction; and family and personal matter have positive relationship with telecommuting concept in Malaysia. Furthermore the study on Malaysian managers' report that factors such as work discipline, improved productivity and quality of work are most likely why firms opt for telecommuting (Karia et al., 2003). These findings are consistent with the studies done by WFH scholars such as Kurland and Bailey (1999), Knight and Westbrook (1999), Fortier (1998), Fitzgerald (1995) and Sullivan (1992).

\section{WFH Development in Malaysia}

Apparently, a few multinational companies in the nation have been adopting WFH for their employees either as full-time or parttime basis. Among them are Amway International, IBM, American Insurance of Association (AIA), Grand soft link computers, Motorola and Texas instrument (Hamsa et al., 1997).

A research carried out by Ndubisi and Kahraman (2005), explores the comparison of teleworking adoption decision processes of multinational firms operating in Malaysia and Malaysian indigenous firms and their survey were focused to the organizations that registered with the Penang Development Corporation (PDC). In the study, the adoption drivers are divided into four main theories which is first, the resource-based view developed around the internal competencies of the firm. Second, the institutional theory that is concerned with the spread of organizational practices within the social framework of norms, values, etc. Third, agency theory, which emphasizes the need for measurability of performance and for performance criteria that employees can influence and lastly the fourth theories, is the societal marketing concept, which prescribes that activity of organizations, should not be conducted at the detriment of the society. In their research, it is stated that the four organizational theories has the capacity to explain teleworking at the organizational level and the key influences on teleworking are management attitude, availability of infrastructure, nature of work, organization design, environmental/ transportation problems, workforce limitations and relative advantage/teleworking and these factors is the variables that led to the adoption of WFH in Malaysian and Multinational firms.

According to them, availability of WFH infrastructure is an important adoption determinant in Malaysian firms but not in multinational firms, while workforce limitations have significant influence on 
adoption in multinational firms but not in Malaysian firms. Malaysia firms relatively have difficulty in WFH adoption from the view of work nature. The results of test of differences show that multinational firms have more positive attitudes towards WFH, perceive greater relative advantage of WFH and more innovative and less structured than Malaysian firms (Ndubisi and Kahraman, 2005).

Recently, in the year 2010, the Ministry of Public Works Malaysia is the very first public institution to implement the concept of working from home with the launching of Work from Home Pilot Programs. The three months programmed involves 39 staff who served as assistant quantity surveyors, draughtsman and technicians. All staff who is working in the Civil Engineering Branch, Structural and Bridge Branch, Architects and Quantity Surveying Branch was selected based on the scope of duties which only involve with the use of computers and the internet (Zakaria, 2010). Department of Public Service is the agency involved that absorbs Work from Home Pilot Programs as part of the transformation of the civil service, but due to the previous salary hikes in 2011, the government has decided to suspend the program.

On the other hand, a research carried out by Adnan (2011); found that the Work from Home Pilot Programs by the Department of Public Service was effective to the participants. Through the data collected, the participants are able to save or reduce the costs involved while working from home such as traveling costs, daily costs such as breakfast, lunch, etc. and also the cost of their child care. While working from home, facilities cost does not give impact to their expenses. When the program was implemented, the participant's productivity increased and it is perceived that the program gives a positive impact to the participants involved.

From the literature on WFH in Malaysia, we can see that both research carried out by Ndubisi and Kahraman (2005); Asaari and Karia (2001) focused on the factors that triggers people to WFH and also the factors that should be taken into consideration towards the implementation of the WFH concept in organizations. It is clear that most of the employees in Malaysia that participated in the research are interested to the implementation of WFH in their organization with job flexibility and satisfaction; and family personal matters are the two factors that led the interest towards WFH (Asaari and Karia, 2001). But then, according Ndubisi and Kahraman (2005), the important adoption determinant in Malaysian firms is the availability of WFH infrastructure. Thus, in order to succeed with the implementation of WFH concept in Malaysian firms, these factors should be essential and necessary for consideration.

The WFH concept not only suitable to be carried out in multinational companies or in manufacturing industry but also has a great potential to be carried out in the construction industry as highlighted by Adnan (2001). Since the literature review gathered from the publication year of 1999 to 2013 it is found that service industry has been identified as the most industry researched for WFH followed by IT industry. Hence, there is ample opportunity to conduct research on WFH in the construction industry.

Based on the literature review the initial development of a theoretical model for $\mathrm{WFH}$ in Malaysian organizations is presented in Figure 1. The model contemplates the major variables from the literature which comprises significant antecedents and an outcome from the literature review will be the initial development of a research framework for WFH in Malaysian organizations. The proposed framework for a successful WFH includes major factors which are significant antecedents and requirements to initiate WFH. All the factors by various authors are grouped into eight main factors which are management, competition, nature of work, attitude, ICT, knowledge, employee and cost. To initiate $\mathrm{WFH}$, the organization should prepare the requirements for their employee to WFH. From the table, it shows that space, employment status, nature of work, working hours, communication/ICT, 
rewards system, home workers occupation, cost sharing and legal issues are the main requirements that the organization must consider before initiating the WFH concept.

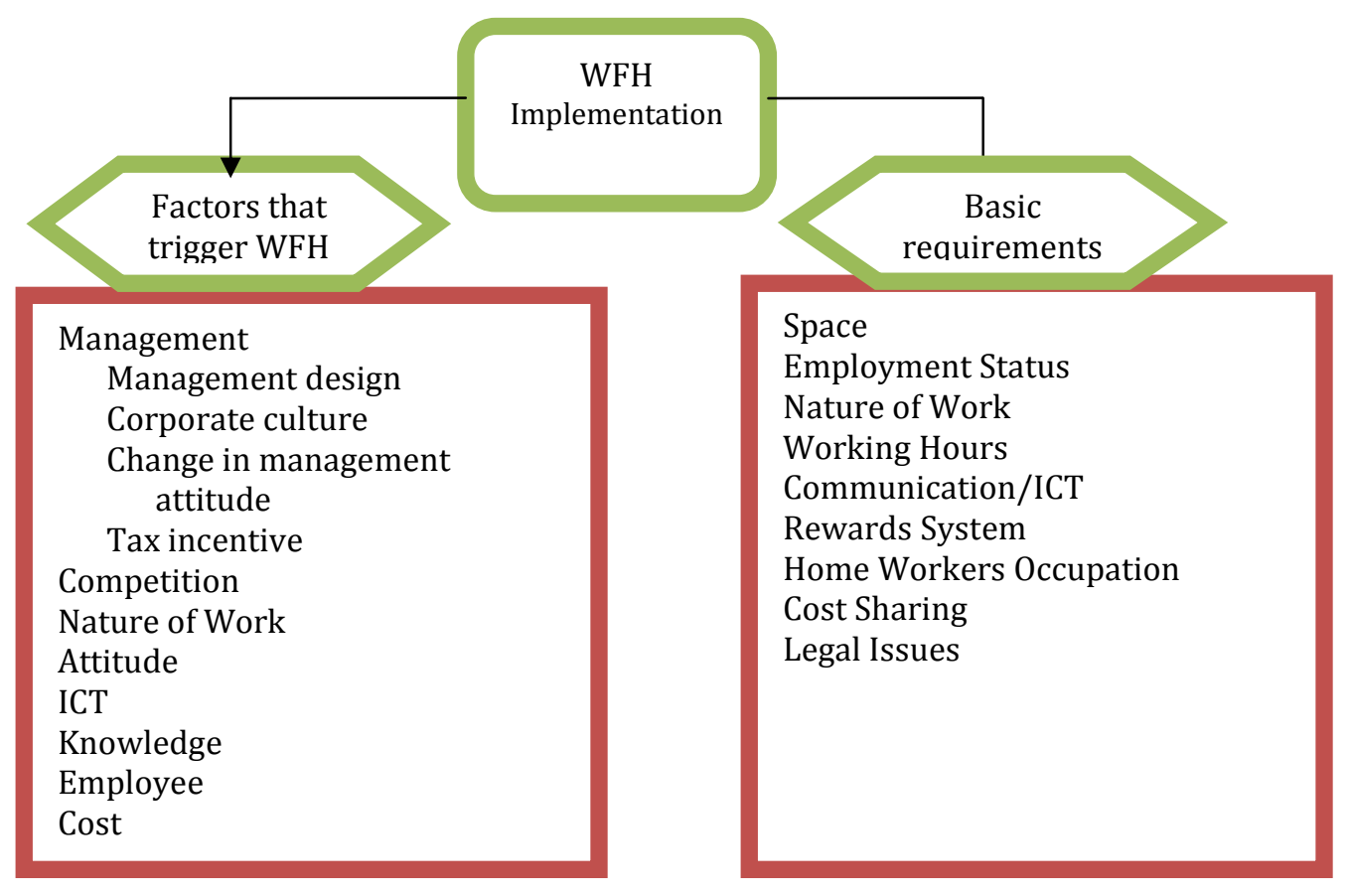

Figure 1: Theoretical Framework of WFH

\section{Conclusion}

Previous studies have identified teleworking as a tool for cutting traffic congestion and protect ecosystem. However the rapid growth of telework is inspired by the growth in knowledge-based economy, rapid progress technology, virtual or green operations and digital society. Given these critical arguments, research on WFH in building sector is still limited. It is apparent that teleworking should be a prominent principle for every firm in Malaysia as it provides the solution for both the economic and environmental improvement. From researchers' viewpoint, working from home concept can be implemented if organizations are aware of the benefits that they can obtain. The literature review carried out may be helpful as a foundation for a future research to be carried out. Therefore, there is ample opportunity to conduct research and contribute to better understanding for both scholars and people in Malaysia. Proper guidelines to organizations have to be in order to make the implementation a success. Furthermore, WFH may be one of the best solutions for all the problems that being faced by the employee nowadays in order to achieve a better work-life balance.

\section{Acknowledgement}

We would like to thank the Ministry of Higher Education, Malaysia and Universiti Sains Malaysia's short term grant for funding this research.

\section{References}

Adnan, N. N. (2011). 'Program Perintis Bekerja Dari Rumah. Sarjana Muda Ukur Bahan,' Universiti Teknologi Malaysia, Skudai, Johor.

Ahmadi, M., Helmes, M. M. \& Ross, T. J. (2000). "Technological Developments: Shaping the Telecommuting Work Environment of the Future," Facilities, 18(1), 83-89.

Asaari, M. H. A. H. \& Karia, N. (2001). "Factors toward Telecommuting: An Exploratory Study over Workers in Service Industry in Penang," Malaysian Management Review, 36 (1), 13-23 
Asaari, M. H. A. H. \& Karia, N. (2001). "Telework Concept: An Exploratory Study Learning from the Malaysia's Experience," Proceedings of Business Information Technology Management (BITWorld2001): Enabling Cultural Awareness, ISBN: 0905304-36-5, 4-6 June 2001, Cairo, Egypt, 13

Baruch, Y. \& Yuen, Y. K. J. (2000). "Inclination to Opt for Teleworking: A Comparative Analysis of United Kingdom versus Hong Kong Employees," International Journal of Manpower, 21(7), 521-539.

[CNN] Cable News Network (1996). "Despite its Advantages, Telework Slow to Catch on," September 11.

Collins, M. (2005). "The (not so Simple) Case for Teleworking: A Study at Lloyd's of London," New Technology, Work \& Employment, 20(2), 115-132.

Damanpour, F. (1991). “Organizational Innovation: A Meta Anlysis of Effects of Determinants and Moderators," Academy of Management Journal, 34(3), 555-590.

Fitzgerald, M. (1995). 'No Places is the Best Place,' Computerworld, Framingham, June, Special Volume/Issue: The 100 best Places to Work.

Fortier, B. (1998). 'Telework Revolution: On-the-job, at Home,' Kiwanis Magazine, September

Golden, T. D. (2006). "The Role of Relationship in Understanding Telecommuter Satisfaction," Journal of Organziational Behavior, 27, 319-340.

Hamsa, A. A. K., Oniyirimba, L. C. \& Ahmad, S. (1997). "An Exploratory Analysis of Factors toward the Emergence of Teleworking in Malaysia," In System Sciences, 1997, Proceedings of the Thirtieth Hawaii International Conference on (Vol. 4, pp. 99-109). IEEE.

Hassan, H. \& Nuruddin, A. R. (2011). "Working From Home Concept for Quantity Surveying Employment," Paper presented at the The Quantity Surveying International Convention 2011, Penang, Malaysia.

Hoon, S. C., Ng, C. \& Mitter, S. (1999). Retrieved from http://www.tcenter.com.my/documents/t elework.pdf

Karia, N. \& Asaari, M. H. A. H. (2003). "Determinants of Telework Implementation in Malaysian Organizations," Proceedings of International Business Information Management, ISBN: 09753393-0-3, Cairo, Egypt, 566-570

Karia, N. \& Asaari, M. H. A. H. (2006). "Telework Implementation toward Virtual Organization In Malaysia," In M. KhosrowPour, Emerging Trend and Challenges in information Technology Management (pp. 784-786). Hershey USA: Idea Group Publishing.

Knight, P. J. \& Westbrook, J. D. (1999). 'Comparing Employees in Traditional Job Structures vs Telecommuting Jobs Using Herzberg's Hygienes \& Motivators,' Engineering Management Journal-Rolla-, 11, 15-20.

Kurland, N. B. \& Bailey, D. E. (1999). "The Advantages and Challenges of Working Here, There, Anywhere, and Anytime," Organizational Dynamics, Autumn, 53-67.

Meyers, J. (1998). 'Free-From Office Work,' Sacramento Business Journal, November 16.

Ndubisi, N. O. \& Kahraman, C. (2005). "Teleworking Adoption Decision-Making Process: Multinational and Malaysian Firms' Comparison," The Journal of Enterprise Information Management, 18(2), 150-168.

Perez, M. P., Sanchez, A. M., Carnicer, M. P. D . L. \& Jimenez, M. J. V. (2004). "The Environmental Impacts of Teleworking: A Model of Urban Analysis and a Case Study," Management of Environmental Quality: An international journal, 15(6), 656-671.

Rogers, E. M. (1983). Diffusion of Innovations, Free Press, New York, NY 
Sayers, J. \& Monin, N. (2005). The Global Garage: Home-Based Business in New Zealand, Auckland: Thomson Dunmore Press.

Shin, B., El Sawy, O. A., Sheng, O. R. L. \& Higa, K. (2000). "Telework: Existing Research and Future Directions," Journal of Organziational Computing and Electronic Commerce, 10(2), 85-101.

Sullivan, Nick (1992). 'Wired for Telework,' Home Office Computing, Boulder, June, Vol.10, Issue 6

Tyre, M. J. \& Orlikowski, W. J. (1993). "Exploiting Opportunities for Technology Improvement in Organisations," Sloan Management Review, 34(1), 13-26.

Warner, M. (1997). 'Working at Home: The Right Way to be a Star in Your Bunny Slippers,' Fortune, 135, 165-6.

Zainuddin, Y., Karia, N. \& Asaari, M. H. A. H. (2003). "Perception of Human Resources Managers on Telecommuting Concept Implementation in Malaysian Firms," Gadjah Mada International Journal of Business, 5(1), 97-107.

Zakaria, O. F. I. (2010). "Kakitangan JKR Mula Bekerja Dari Rumah," Utusan [Online], [Retrieved 8 June 2012], http://www.utusan.com.my/utusan/info.a

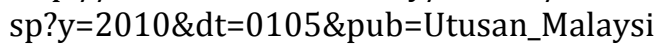
a\&sec=Dalam_Negeri\&pg=dn_16.htm 